\title{
Titanium dioxide (TiO2) nanoparticles were synthesised and characterized in order to test their effectiveness against two predatory insects
}

\author{
Muhammad Nadeem Khan ${ }^{1}$, Muhammad Tahir ${ }^{2}$, Samdullah ${ }^{3}$ Imran Ahmad Khan ${ }^{2}$, Waheb Aoun Jafari ${ }^{4}$, \\ Shehreen Fatima ${ }^{5}$, Muhammad Ishaq ${ }^{4}$, Muhammad Adnan ${ }^{5}$, Muhammad Aqib Mukhtar ${ }^{4}$ \\ ${ }^{1}$ Department of chemistry, University of Lahore, Pakistan \\ ${ }^{2}$ Department of chemistry, government college university Faisalabad 38000, Pakistan \\ ${ }^{3}$ Department of chemistry, Shaheed Benazir Bhutto University Sheringal Dir Upper, Pakistan \\ ${ }^{4}$ Department of chemistry, University of Agriculture Faisalabad, Pakistan \\ ${ }^{5}$ Department of chemistry, Bahauddin Zakariya University, Multan, Pakistan \\ DOI: 10.29322/IJSRP.11.12.2021.p12076 \\ http://dx.doi.org/10.29322/IJSRP.11.12.2021.p12076
}

\begin{abstract}
Nanosciences and microbiology are the research of extremely small objects on a nm scale. Tribolium Castaneum and Trogoderma Granarium isolates of various ages have been reported from the Lahore commodity market. For each of the two insects, the population had been acclimated to the laboratory. To maintain a homogenous population, pupa of the same age were collected during insect development and placed in separate plastic jars until adult emergence ( 2 weeks). Following the extraction of plant components, the biosynthesis of titanium-particles was carried out according to the standard technique. Toxicity Bioassays were conducted using three different plant extract concentrations (5, 10\%, and 15\%) (For both of the basic plant oils as well as nano-particles). After 24, 48, and 72 hours of care, mortality was determined. Tribolium Castaneum has the highest mortality rate (15.10\%) and the lowest mortality rate $(15.10 \%)$. (46.12\%). The highest death rates were 40.40 and 33.68 percent for TiO2 nanoparticles, respectively. Repellency bioassays using the area preference method (TiO2) revealed $86.10 \%$ and 72.64 percent repellency against Tribolium Castaneum and Trogoderma Granarium, respectively. The data from all bioassays were analyzed using a factorial design with a CRD statistical design.
\end{abstract}

\section{INTRODUCTION}

$\mathrm{N}$ anosciences is a rapidly emerging and technologically advanced field of study that encompasses fundamental elements and recognizes and advances the evolving process of processing materials that include only one component. This has the ability to control individual molecules and atoms. This is one of the most significant technological advancements of the previous few decades [1]. Nanoparticles (Nanopowder, Nano ring, Nanocrystal) are the Nanoscience small building block [2]. It also used as a biomedical, optical and electronic field. The nanoparticle has been work very successfully in the field of medicine, environmental sciences and food processing [3]. Owing to its modern use such as environmental protection, data management, genetics, beauty products, medicines owing to their electronic, physical and magnetic properties, nanoparticles have recently been commercial[4]. In fact, the biosynthesis of nanoparticles is environmentally sustainable, because it can shape the toxic, costly chemicals without the use of them [5]This has also been used as a highly conductive and semi-conductor, medical equipment, sensor insulation, catalytic agents and as a pesticide as well. Nanocarriers are designed to reduce the amount of operation and delay the kinetics of agrochemicals releases [6].

Store grains and their products are attacked by a variety of insects, resulting in significant losses [7]. Crop storage accounted for about 9 percent of losses in industrialized countries and 20 percent in more emerging countries[8].All stored grain insect pests most disreputable is red flour beetle Tribolium castaneum (Herbst) (Coleoptera: Tenebrionidae), which is a pervasive pest of the store commodities like wheat flour and crushed cereals, is also the cosmopolitan and most destructive insect pest [9]. T. granarium serious pest in the product which retained in the hot and dry conditions, with high relative humidity gives an acute effect on the population and building-up the sound grain pest[10]. Their adults are not dangerous but their larvae are most destructive but their adults are very harmless [11].These larvae feed on sound grain and consume the entire kernel, leaving behind empty grains and husks. The quality of grains reduced due to frass and excreta in damage grains, it can create a negative effects on the atmosphere including infested grain have an adverse impact on human safety [12].

T. Granarium prevents grain from germinating by absorbing different nutrients while it feeds on larvae [13]. Other chemicals like pyrethroids are being also used for the control of stored grains insect-pests, but consistent use of theses insecticides may lead to serious problems related to biochemical and hematological changes in human beings[14]. Conventional insecticides also pose a hazardous effect on non-target organisms including beneficial insects [15]. Due to the potential insecticidal properties botanical is the possible alternative source of pest control[16]. The effect of plant products showed insecticidal, repellent and antifeedant effects against insect pests[17]. In the past years, $T$. castaneum pest can be controlled by Polyethalyen glycol and diatomaceous earth but garlic essential oil can be act as a reducing agent [18]. 


\section{Preparation of Titanium oxide Nano-particles}

To begin, we can prepare the silver nanoparticles in the following manner: Take the powdered leaves of R.communis, Jatropha curcus, and Citrus paradisi acquired at a local market. Deionized water used in all experiments, I took 10g of R. communis, Jatropha curcus, and Citrus paradise extracts by using weight balance, which can be boiled in $100 \mathrm{ml}$ distilled water in $250 \mathrm{ml}$ conical flask. Then this extract was cooled at room temperature, Filter into the No. 1 filter paper of Whatman. It filtrate was an act of minimizing and stabilization agent for the preparation of nanoparticles of titanium oxide. Ammonium solution will be added to Titanium oxide (solution followed by the addition of plant material extract 1-10ml) as described in [19].

\section{Bioassay of $\mathrm{TiO} 2$ nanoparticles}

We can employ a green synthesis method to create titanium nanoparticles. $10 \mathrm{ml}$ of plant oil from the stock solution cooked for 30 minutes at $90^{\circ} \mathrm{C}$ in $50 \mathrm{ml}$ double distilled water. Following that, we can filter this extract using Whattman filter paper. We can prepare the $1 \mathrm{mM}$ solution of the $\mathrm{TiO}_{2}$ aqueous solution which can boil at $25^{\circ} \mathrm{C}$ for 2 hours. Add $10 \mathrm{ml}$ of aqueous plant extract into the $20 \mathrm{ml}$ of $1 \mathrm{mM} \mathrm{TiO} 2$ solution at $25^{\circ} \mathrm{C}$ heated with $200 \mathrm{rpm}$ stirring for 4 hours. After 4 hours, the colors of the solution will be changed into lite green and then converted into colorless form. Then we can put the extract for 24 hours in oven for drying at $80^{\circ} \mathrm{C}$. Then these precipitates were drying and stored for further analysis [20].

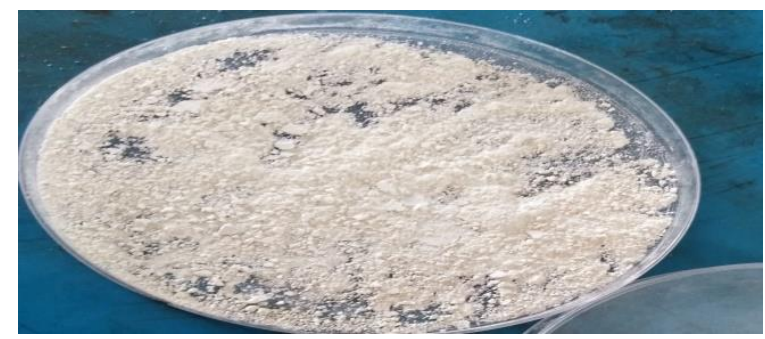

Figure 1.1 (Titanium-Dioxide Dried nano-composites)

Table 1: Change in solution color when forming Titanium dioxide nanoparticles using Jatropha curcus, Citrus paradise, and R the herb extracts of Communis.

\begin{tabular}{|l|l|l|l|l|}
\hline Solution & Before Reduction & After Reduction & Color intensity & Time \\
\hline Jatropha curcus & Dark Yellow & & & \\
\hline $\begin{array}{l}1 \mathrm{mM} \text { solution of } \\
\mathrm{TiO}_{2}\end{array}$ & Transparent & Yellow & + & Immediately \\
\hline & & Pale Yellow & ++ & After 7 hours \\
\hline & & Off white & +++ & After 24 hours \\
\hline Citrus paradise & Lite Yellow & & & \\
\hline $\begin{array}{l}1 \mathrm{mM} \text { solution of } \\
\mathrm{TiO}_{2}\end{array}$ & Transparent & Green & + & Immediately \\
\hline & & Yellowish & ++ & After 7 hours \\
\hline & & Pale yellow white & +++ & After 24 hours \\
\hline$R$. communis & & Yellow & + & Immediately \\
\hline $\begin{array}{l}1 \mathrm{mM} \text { solution of } \\
\mathrm{TiO}_{2}\end{array}$ & Transparent & Pale Yellow & ++ & After 7 hours \\
\hline & & Off white & +++ & After 24 hours \\
\hline
\end{tabular}




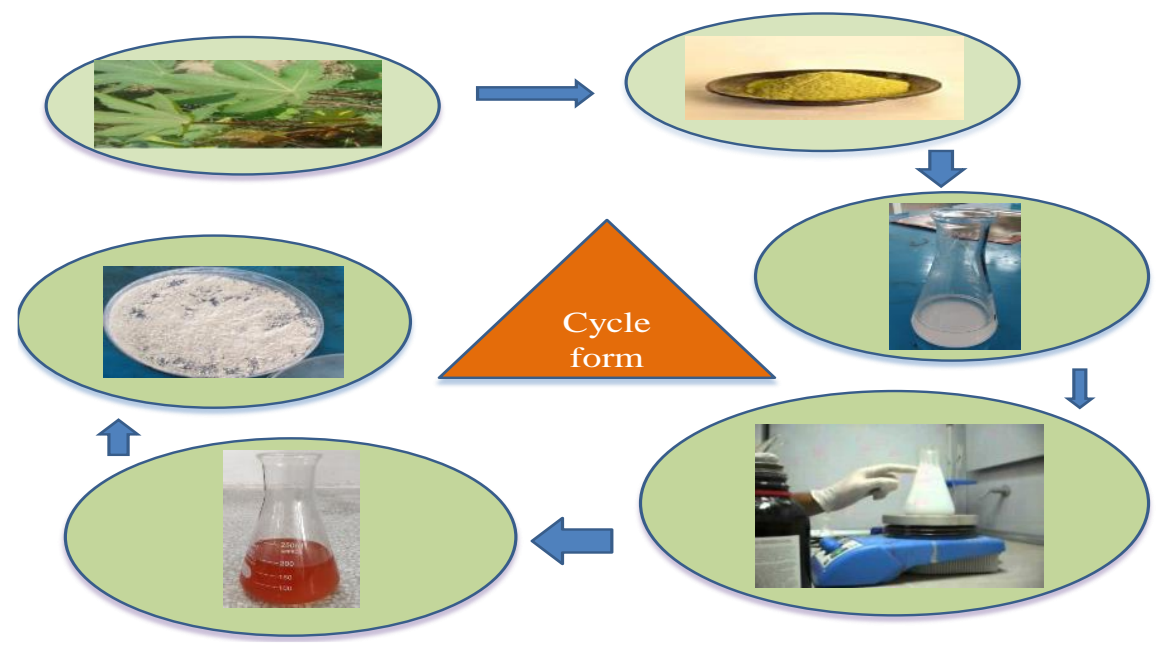

Figure 1.2: Sketch Explanation

\section{CHARACTERIZATION OF NANOPARTICLES}

We will use absorption spectra to determine the optimal output of silver nanoparticles. Through the use of a UV-visible spectrophotometer (HITACHI, Model U-2800) we will detect the wavelength of SNP; deionized water serves as a blank solution. The ultimate top point of silver nanoparticle will be in an air-dried shape and atomic-force-microscopy (Model-Nanosurf easy scan 2 AFM, Switzerland) as defined in [21] will be able to classify it.

\section{TOXICITY BIOASSAY}

Three herb extracts can be dissolved in the stock solution by using four solvents, their concentration is $(15,10$ and $5 \%)$. The concentration is to be hands-on smashed seeds, shook for better concentration delivery. This will allow air to be dried and placed into small plastic bottles. Both species, adults, will be released as defined in a controlled diet that includes jars [22].

\section{Repellency}

The mean percentage of repellence was calculated by using a preferential approach. After the filter paper was divided into two parts, one half of each paper was prepared with the extracts from the plants and acetone. After some time, the solution would evaporate, so two halves were inserted and put in a Petri bowl. 20 Tribolium castanium and Trogoderma granarium adults were re-allocated to a filter paper that was screened in the middle. Repellency data were reported respectively after 24, 48 and 72 hours [23].

\section{Results and discussion}

The studies have been repeated in thrice along with the control factor under different designs Fully Randomized Design (CRD) with all the various treatments. Plant extracts have been used at three different concentration levels, i.e. 5, 10 and $15 \%$, mortality results should be observed after 24, 48 and 72 hours of application of medication. At the same product type/rate of plant extracts, we had independently performed the experiments on repellence and growth inhibition. The data were collected about larval inhibition, pupa; inhibition and adult inhibition at daily intervals, while the repellency data was reported at $24 \mathrm{hrs}$.

\section{WITH Titanium dioxide NANO-PARTICLES against Tribolium castanium}

\section{MORTALITY DATA AFTER EXPOSURE OF 24 HRS}

To measure T-mortality. Castaneum, homogeneous adults were introduced into small plastic jars on a controlled diet. Adults were required to feed on controlled diets, and mortality data were reported. Wheat grains were used as diet and three concentrations of each plant extract were used viz., 5, 10 and 15\%. Mortality data were recorded for 24, 48 and $72 \mathrm{~h}$ of the exposure period. Insects were held at $30 \pm 2^{\circ} \mathrm{C}$ and $60 \pm 5$ per cent RH in incubators for mortality assessment. They repeated each operation and control three times.

Table 2.1 Reveals the variance analysis (ANOVA) of data on mean T percent mortality. Castaneum at various Jatropha curcus, Citrus paradise, and $\mathrm{R}$ concentrations. Commons.

Data showed that main effects, plants $(\mathrm{F}=4.66 ; \mathrm{df}=1: \mathrm{p}<0.05)$ and concentration $(\mathrm{F}=11.10 \mathrm{df}=; 2 \mathrm{p}<0.05)$ were significant regarding mortality values of $T$. castaneum after an exposure period of 24 hours. 
Table 2.1 Analysis of variance (ANOVA) of the data concerning \% mortality of Tribolium castaneum (Herbst) for Titanium dioxidebased nano-particles

\begin{tabular}{|l|l|l|l|l|}
\hline S.O.V & DF & SS & MSS & F value \\
\hline Plant & 2 & 555.807 & 277.904 & $38.4000^{* *}$ \\
\hline Concentration(Conc.) & 2 & 480.691 & 240.345 & $33.2103^{* *}$ \\
\hline Plant*Concentration & 4 & 65.422 & 16.355 & 2.2600 \\
\hline Error & 18 & 130.267 & 7.237 & \\
\hline Total & 26 & 1232.187 & & \\
\hline
\end{tabular}

Table 2.2 Comparison of the mean percentage mortality of Tribolium castaneum after exposure to different concentrations of plant extracts after $24 \mathrm{hrs}$

\begin{tabular}{|l|c|}
\hline Concentrations (\%) & Mean percentage of mortality \pm SE \\
\hline $\mathbf{5}$ & $5.81 \pm 1.49$ \\
\hline $\mathbf{1 0}$ & $14.18 \pm 2.30$ \\
\hline $\mathbf{1 5}$ & $22.58 \pm 4.77$ \\
\hline
\end{tabular}

Data in table 2.1 Represents the insecticidal effect of different concentrations of 3 different oil against Tribolium castaneum. The experimental data revealed that maximum mortality (22.58\%) at $15 \%$ was recorded. The mean mortality was 14.18 per cent at 10 per cent concentration and 5.81 per cent death at 5 per cent plant extract concentration was observed. From this, it is inferred that mortality only increased with a rise in concentrations of the 3 different plant oil and shows also that concentration has a major impact on the mean percent mortality rate of $\mathrm{T}$. castaneum.

2.3 Comparison of the mean percentage mortality of Tribolium castaneum after exposure to different plant extracts after 24 hrs

\begin{tabular}{|l|c|}
\hline Concentrations (\%) & Mean percentage of mortality \pm SE \\
\hline P1 & $6.67 \pm 1.44$ \\
\hline P2 & $11.12 \pm 1.82$ \\
\hline P3 & $24.80 \pm 4.48$ \\
\hline
\end{tabular}

Table 2.3. For percent mean mortality values of different plant extracts at different concentration levels showed that extracts of $R$. communis and Jatropha curcus gave mortality values 24.80 and $11.12 \%$, correspondingly. While the least mortality $6.67 \%$ was given by extract of Citrus paradise. 
2.4 Comparative mean percentage mortality of Tribolium castaneum after exposure to different concentrations of plant extracts after $24 \mathrm{hrs}$

\begin{tabular}{|c|c|}
\hline Plant extracts x Concentrations (\%) & (\%) Mean Mortality \pm SE \\
\hline Citrus paradise $\mathrm{x} 5$ & $1.67 \pm 1.67 \mathrm{~g}$ \\
\hline Citrus paradise $\mathrm{x} 10$ & $8.34 \pm 1.67$ efg \\
\hline Citrus paradise $\mathrm{x} 15$ & $10.00 \pm 0.00 \mathrm{def}$ \\
\hline Jatropha curcus $\times 5$ & $5.00 \pm 0.00 \mathrm{fg}$ \\
\hline Jatropha curcus $\mathrm{x} 10$ & $11.67 \pm 1.67 \mathrm{~cd}$ \\
\hline Jatropha curcus $\mathrm{x} 15$ & $16.67 \pm 1.67 \mathrm{bc}$ \\
\hline Ricinus communis $\mathrm{x} 5$ & $10.77 \pm 1.68 \mathrm{de}$ \\
\hline Ricinus communis $\mathrm{x} 10$ & $22.56 \pm 1.68 \mathrm{~b}$ \\
\hline Ricinus communis $\mathrm{x} 15$ & $41.07 \pm 1.68 \mathrm{a}$ \\
\hline
\end{tabular}

Table 2.4 showed the interaction between different concentrations (5, 10 and 15\%) and different exposure periods. Mean mortality of $T$. castaneum was given in percentage by the application of an extract of Ricinus communis, Jatropha curcus, Citrus paradise oil along with the standard error in table 2.4.

The mean comparison of percentage mortality values of $T$. castaneum at different concentrations of selected plant extract was highest at maximum concentration. Extract of Ricinus communis gave the highest mean mortality revealed that maximum mortality $(41.07 \%)$ at $15 \%$ was recorded. The mean mortality was $22.56 \%$ at $10 \%$ concentration and $10.78 \%$ mortality was detected at 5 percent of the plant extract concentration. Extract of Jatropha curcus gave the mean mortality revealed that maximum mortality (16.67\%) at $15 \%$ was recorded. The mean mortality was $11.67 \%$ at $10 \%$ concentration and $5.00 \%$ mortality was observed at 5 per cent plant extract concentration. Extract of Citrus paradise gave the mean mortality revealed that maximum mortality $(10.00 \%)$ at $15 \%$ was recorded. The mean mortality was $8.34 \%$ at $10 \%$ concentration and $1.67 \%$ mortality of the plant extracts was estimated at 5 percent. The result given showed substantial correlation between exposure time and concentration. From the results, we inferred that mortality values were rising slowly, with a rise in plant extract concentration.

\section{MORTALITY DATA AFTER EXPOSURE OF 48 HRS}

Table 3.1 Analysis of variance (ANOVA) of the data concerning \% mortality of Tribolium castaneum (Herbst) for Titanium dioxidebased nano-particles

\begin{tabular}{|l|l|l|l|l|}
\hline S.O.V & DF & SS & MSS & F value \\
\hline Plant & 2 & 1608.555 & 804.278 & $123.0181^{* *}$ \\
\hline Concentration(Conc.) & 2 & 1265.198 & 632.599 & $96.7590^{* *}$ \\
\hline Plant*Concentration & 4 & 457.108 & 114.277 & $17.4792^{*}$ \\
\hline
\end{tabular}




\begin{tabular}{|l|l|l|l|l|}
\hline S.O.V & DF & SS & MSS & F value \\
\hline Error & 18 & 117.682 & 6.538 & \\
\hline Total & 26 & 3448.543 & & \\
\hline
\end{tabular}

Table 3.2 Comparison of the mean percentage mortality of Tribolium castaneum after exposure to different concentrations of plant extracts after $48 \mathrm{hrs}$

\begin{tabular}{|l|c|}
\hline Concentrations (\%) & Mean percentage mortality \pm SE \\
\hline $\mathbf{5}$ & $5.81 \pm 1.49$ \\
\hline $\mathbf{1 0}$ & $14.18 \pm 2.30$ \\
\hline $\mathbf{1 5}$ & $22.58 \pm 4.77$ \\
\hline
\end{tabular}

Data in table 3.1. Represents the insecticidal effect of different concentrations of 3 different oil against Tribolium castaneum. The experimental data revealed that maximum mortality $(22.58 \%)$ at $15 \%$ was recorded. The mean mortality was $14.18 \%$ at $10 \%$ concentration and $5.81 \%$ mortality was observed at 5 per cent plant extract concentration. Through this, it is inferred that mortality only increased with a rise in concentrations of the 3 separate plant oil and indicates also that concentration has a major impact on the mean percent mortality rate of $\mathrm{T}$. Castaneum.

3.3 Comparison of the mean percentage mortality of Tribolium castaneum after exposure to different plant extracts after $48 \mathrm{hrs}$

\begin{tabular}{|l|c|}
\hline Concentrations (\%) & Mean percentage of mortality \pm SE \\
\hline P1 & $6.67 \pm 1.44$ \\
\hline P2 & $11.12 \pm 1.82$ \\
\hline P3 & $24.80 \pm 4.48$ \\
\hline
\end{tabular}

Table 3.1 For percent mean mortality values of different plant extracts at different concentration levels showed that extracts of $R$. communis and Jatropha curcus gave mortality values 24.80 and $11.12 \%$, correspondingly. While the least mortality $6.67 \%$ was given by extract of Citrus paradise.

3.4 Comparative mean percentage mortality of Tribolium castaneum after exposure to different concentrations of plant extracts after $48 \mathrm{hrs}$

\begin{tabular}{|l|c|}
\hline Plant extracts x Concentrations (\%) & (\%) Mean Mortality \pm SE \\
\hline Citrus paradise x 5 & $1.67 \pm 1.67 \mathrm{~g}$ \\
\hline Citrus paradise x 10 & $8.34 \pm 1.67 \mathrm{efg}$ \\
\hline
\end{tabular}




\begin{tabular}{|c|c|}
\hline Plant extracts x Concentrations (\%) & (\%) Mean Mortality \pm SE \\
\hline Citrus paradise $\mathrm{x} 15$ & $10.00 \pm 0.00 \mathrm{def}$ \\
\hline Jatropha curcus $\mathrm{x} 5$ & $5.00 \pm 0.00 \mathrm{fg}$ \\
\hline Jatropha curcus $\mathrm{x} 10$ & $11.67 \pm 1.67 \mathrm{~cd}$ \\
\hline Jatropha curcus x 15 & $16.67 \pm 1.67 \mathrm{bc}$ \\
\hline Ricinus communis $\mathrm{x} 5$ & $10.77 \pm 1.68 \mathrm{de}$ \\
\hline Ricinus communis $\mathrm{x} 10$ & $22.56 \pm 1.68 \mathrm{~b}$ \\
\hline Ricinus communis $\mathrm{x} 15$ & $41.07 \pm 1.68 \mathrm{a}$ \\
\hline
\end{tabular}

Table 3.4 showed the interaction between different concentrations (5, 10 and 15\%) and different exposure periods. Mean mortality of $T$. castaneum was given in percentage by the application of an extract of Ricinus communis, Jatropha curcus, Citrus paradise oil along with the standard error in table 3.4

The mean comparison of percentage mortality values of $T$. castaneum at different concentrations of selected plant extract was highest at maximum concentration. Extract of Ricinus communis gave the highest mean mortality revealed that maximum mortality $(41.07 \%)$ at $15 \%$ was recorded. The mean mortality was $22.56 \%$ at $10 \%$ concentration and $10.78 \%$ mortality concentration of plant extracts was observed at 5 per cent. Extract of Jatropha curcus gave the mean mortality revealed that maximum mortality (16.67\%) at $15 \%$ was recorded. The mean mortality was $11.67 \%$ at $10 \%$ concentration and $5.00 \%$ mortality the plant extract concentration was measured at 5 per cent. Extract of Citrus paradise gave the mean mortality revealed that maximum mortality $(10.00 \%)$ at $15 \%$ was recorded. The mean mortality was $8.34 \%$ at $10 \%$ concentration and $1.67 \%$ mortality the concentration of plant extracts was measured at 5 per cent. The result given showed substantial correlation between exposure time and concentration. From the results, we concluded that mortality values were rising slowly, with a rise in plant extract concentration.

\section{MORTALITY DATA AFTER EXPOSURE OF 72 HRS}

Table 4.1 Analysis of variance (ANOVA) of the data concerning \% mortality of Tribolium castaneum (Herbst) for Titanium dioxidebased nanoparticles

\begin{tabular}{|l|l|l|l|l|}
\hline S.O.V & DF & SS & MSS & F value \\
\hline Plant & 2 & 967.452 & 483.726 & $94.106^{* *}$ \\
\hline Concentration & 2 & 1575.647 & 787.823 & $153.266^{* *}$ \\
\hline Plant*Concentration & 4 & 275.269 & 68.817 & $13.388^{*}$ \\
\hline Error & 18 & 92.525 & 5.140 & \\
\hline Total & 26 & & & \\
\hline
\end{tabular}


Table 4.2. Comparison of the mean percentage mortality of Tribolium castaneum after exposure to different concentrations of plant extracts after $72 \mathrm{hrs}$

\begin{tabular}{|l|l|}
\hline Concentrations (\%) & Mean percentage of mortality \pm SE \\
\hline $\mathbf{5}$ & $9.04 \pm 0.87 \mathrm{c}$ \\
\hline $\mathbf{1 0}$ & $19.65 \pm 2.41 \mathrm{~b}$ \\
\hline $\mathbf{1 5}$ & $27.69 \pm 3.45 \mathrm{a}$ \\
\hline
\end{tabular}

Data in table 4.1. Represents the insecticidal effect of different concentrations of 3 different oil against Tribolium castaneum. The experimental data revealed that maximum mortality (27.69\%) at 15\% was recorded. The mean mortality was $9.04 \%$ at $5 \%$ concentration and $19.65 \%$ mortality was found at a plant extract concentration of 10 per cent. From this, it is concluded that Mortality increased even with a rise in concentrations of the three different plant oil and also indicates that concentration has a major impact on the mean percent mortality rate of $\mathrm{T}$. castaneum.

4.3 Comparison of the mean percentage mortality of Tribolium castaneum after exposure to different plant extracts after $72 \mathrm{hrs}$

\begin{tabular}{|l|c|}
\hline Concentrations (\%) & Mean percentage of mortality \pm SE \\
\hline P1 & $11.89 \pm 1.70 \mathrm{c}$ \\
\hline P2 & $18.00 \pm 2.29 \mathrm{~b}$ \\
\hline P3 & $26.49 \pm 4.34 \mathrm{a}$ \\
\hline
\end{tabular}

Table 4.3. For percent mean mortality values of different plant extracts at different concentration levels showed that extracts of $R$. communis and Jatropha curcus gave mortality values 26.49 and $18.00 \%$, corresponding. While the least mortality $11.89 \%$ was given by extract of Citrus paradise.

Comparative mean percentage mortality of Tribolium castaneum after exposure to different concentrations of plant extracts after $72 \mathrm{hrs}$

\begin{tabular}{|l|c|}
\hline Plant extracts x Concentrations (\%) & (\%) Mean Mortality \pm SE \\
\hline Citrus paradise x 5 & $6.334 \pm 1.34 \mathrm{~g}$ \\
\hline Citrus paradise x 10 & $12.00 \pm 1.15 \mathrm{efg}$ \\
\hline Citrus paradise x 15 & $17.34 \pm 1.20 \mathrm{def}$ \\
\hline Jatropha curcus x 5 & $9.67 \pm 0.34 \mathrm{fg}$ \\
\hline Jatropha curcus $\times 10$ & $19.00 \pm 0.57 \mathrm{~cd}$ \\
\hline Jatropha curcus $\times 15$ & $25.34 \pm 0.67 \mathrm{bc}$ \\
\hline
\end{tabular}




\begin{tabular}{|l|c|}
\hline Plant extracts x Concentrations (\%) & $(\%)$ Mean Mortality \pm SE \\
\hline Ricinus communis x 5 & $11.12 \pm 1.16 \mathrm{de}$ \\
\hline Ricinus communis x 10 & $27.94 \pm 2.04 \mathrm{~b}$ \\
\hline Ricinus communis x 15 & $40.40 \pm 2.10 \mathrm{a}$ \\
\hline
\end{tabular}

Table 4.2. Showed the interaction between different concentrations (5, 10 and 15\%) and different exposure periods. Mean mortality of $T$. castaneum was given in percentage by the application of an extract of Ricinus communis, Jatropha curcus, Citrus paradise oil along with the standard error in table 4.2 .

The mean comparison of percentage mortality values of $T$. castaneum at different concentrations of selected plant extract was highest at maximum concentration. Extract of Ricinus communis gave the highest mean mortality revealed that maximum mortality (40.40\%) at $15 \%$ was recorded. The mean mortality was $27.94 \%$ at $10 \%$ concentration and $11.12 \%$ mortality was observed at 5 per cent plant extract concentration. Extract of Jatropha curcus gave the mean mortality revealed that maximum mortality $(25.34 \%)$ at $15 \%$ was recorded. The mean mortality was $19.00 \%$ at $10 \%$ concentration and $9.67 \%$ mortality of the plant extracts was observed at 5 percent. Extract of Citrus paradise gave the mean mortality revealed that maximum mortality (17.34\%) at $15 \%$ was recorded. The mean mortality was $12.00 \%$ at $10 \%$ concentration and $6.34 \%$ mortality was observed at 5 percent of the plant extract concentration. The result given showed substantial interaction between exposure time and concentration. From the analysis, we observed that mortality values were rising slowly, with a rise in plant extract concentration.

\section{WITH Titanium dioxide NANO-PARTICLES against Trogoderma granarium}

\section{MORTALITY DATA AFTER EXPOSURE OF 24 HRS}

To evaluate the mortality of T. granarium, homogenous adults were released on the treated diet in small plastic jars. We found from the study that mortality values were increasing gradually, with a rise in concentration of plant extracts. Wheat grains were used as diet and three concentrations of each plant extract were used viz., 5, 10 and 15\%. Mortality data were recorded for 24, 48 and $72 \mathrm{~h}$ of the exposure period. Insects were held at $30 \pm 2 \mathrm{oC}$ and $60 \pm 5$ per cent $\mathrm{RH}$ in incubators for mortality assessment. They repeated each treatment and control three times.

Table 5.1 reveals the analysis of variance (ANOVA) of data regarding the mean percentage mortality of $T$. granarium at different concentrations of Jatropha curcus, Citrus paradise, and R. communis. Data showed that main effects, plants ( $\mathrm{F}=4.66 ; \mathrm{df}=1: \mathrm{p}<0.05)$ and concentration $(\mathrm{F}=11.10 \mathrm{df}=; 2 \mathrm{p}<0.05)$ were significant regarding mortality values of $T$. castaneum after an exposure period of 24 hours.

Table 5.1. Analysis of variance (ANOVA) of the data concerning $\%$ mortality of $T$. granarium (Herbst) for Titanium dioxide-based nanoparticles

\begin{tabular}{|l|l|l|l|l|}
\hline S.O.V & DF & SS & MSS & F value \\
\hline Plant & 2 & 871.817 & 435.909 & $114.508 * *$ \\
\hline Concentration & 2 & 970.047 & 485.023 & $127.409 * *$ \\
\hline Plant*Concentration & 4 & 180.138 & 45.035 & $11.830 *$ \\
\hline Error & 18 & 68.523 & 3.807 & \\
\hline Total & 26 & 2090.525 & & \\
\hline
\end{tabular}


Table 5.2 Comparison of the mean percentage mortality of Trogoderma granarium after exposure to different concentrations of plant extracts after $24 \mathrm{hrs}$

\begin{tabular}{|l|c|}
\hline Concentrations (\%) & Mean percentage of mortality \pm SE \\
\hline $\mathbf{5}$ & $6.36 \pm 1.01$ \\
\hline $\mathbf{1 0}$ & $16.41 \pm 2.36$ \\
\hline $\mathbf{1 5}$ & $20.66 \pm 3.00$ \\
\hline
\end{tabular}

Data in table 5.1. Represents the insecticidal effect of different concentrations of 3 different oil against Trogoderma granarium. The experimental data revealed that maximum mortality $(20.66 \%)$ at $15 \%$ was recorded. The mean mortality was $6.36 \%$ at $5 \%$ concentration and $16.41 \%$ mortality was observed at a concentration of 10 per cent of plant extracts. From this, it is inferred that mortality only increased with a rise in concentrations of the 3 different plant oil and shows also that concentration has a major impact on the mean percent mortality rate of $\mathrm{T}$. granarium.

5.3 Comparison of the mean percentage mortality of Trogoderma granarium after exposure to different plant extracts after $24 \mathrm{hrs}$

\begin{tabular}{|l|c|}
\hline Concentrations (\%) & Mean percentage of mortality \pm SE \\
\hline P1 & $7.23 \pm 1.12$ \\
\hline P2 & $15.12 \pm 2.20$ \\
\hline P3 & $21.09 \pm 3.29$ \\
\hline
\end{tabular}

Table 5.2. For percent mean mortality values of different plant extracts at different concentration levels showed that extracts of $R$. communis and Jatropha curcus gave mortality values 21.09 and $15.12 \%$, corresponding. While the least mortality $7.23 \%$ was given by extract of Citrus paradise.

5.4 Comparative mean percentage mortality of Trogoderma granarium after

exposure to different concentrations of plant extracts after $24 \mathrm{hrs}$

\begin{tabular}{|l|c|}
\hline Plant extracts x Concentrations (\%) & (\%) Mean Mortality \pm SE \\
\hline Citrus paradise x 5 & $3.34 \pm 1.67 \mathrm{~g}$ \\
\hline Citrus paradise x 10 & $8.34 \pm 0.34 \mathrm{efg}$ \\
\hline Citrus paradise x 15 & $10.00 \pm 0.00 \mathrm{def}$ \\
\hline Jatropha curcus x 5 & $7.00 \pm 1.00 \mathrm{fg}$ \\
\hline Jatropha curcus $\times 10$ & $17.00 \pm 1.52 \mathrm{~cd}$ \\
\hline Jatropha curcus $\times 15$ & $21.34 \pm 0.89 \mathrm{bc}$ \\
\hline
\end{tabular}




\begin{tabular}{|l|c|}
\hline Plant extracts x Concentrations (\%) & $(\%)$ Mean Mortality \pm SE \\
\hline Ricinus communis x 5 & $8.75 \pm 0.89 \mathrm{de}$ \\
\hline Ricinus communis x 10 & $23.90 \pm 1.78 \mathrm{~b}$ \\
\hline Ricinus communis x 15 & $30.63 \pm 0.67 \mathrm{a}$ \\
\hline
\end{tabular}

Table 5.5 showed the interaction between different concentrations (5, 10 and 15\%) and different exposure periods. Mean mortality of $T$. granarium was given in percentage by the application of an extract of Ricinus communis, Jatropha curcus, Citrus paradise oil along with the standard error in table 5.5.

The mean comparison of percentage mortality values of $T$. granarium at different concentrations of selected plant extract was highest at maximum concentration. Extract of Ricinus communis gave the highest mean mortality revealed that maximum mortality $(30.63 \%)$ at $15 \%$ was recorded. The mean mortality was $23.90 \%$ at $10 \%$ concentration and $8.75 \%$ mortality was observed at 5 per cent plant extract concentration. Extract of Jatropha curcus gave the mean mortality revealed that maximum mortality (21.34\%) at $15 \%$ was recorded. The mean mortality was $17.00 \%$ at $10 \%$ concentration and $7.00 \%$ mortality concentration of plant extracts was observed at 5 per cent. Extract of Citrus paradise gave the mean mortality revealed that maximum mortality (10.00\%) at $15 \%$ was recorded. The mean mortality was $8.34 \%$ at $10 \%$ concentration and $3.34 \%$ mortality was observed at $5 \%$ concentration of the plant extracts. The given outcome showed that the interaction of exposure time and concentration was significant. From the findings, we observed that mortality values were rising slowly, with a rise in plant extract concentration.

\section{MORTALITY DATA AFTER EXPOSURE OF 48 HRS}

Table 6.1 Analysis of variance (ANOVA) of the data concerning \% mortality of $T$. granarium (Herbst) for Titanium dioxide-based nanoparticles

\begin{tabular}{|l|l|l|l|l|}
\hline S.O.V & DF & SS & MSS & F value \\
\hline Plant & 2 & 580.743 & 290.371 & $80.454^{* *}$ \\
\hline Concentration & 2 & 717.708 & 358.854 & $99.429 * *$ \\
\hline Plant*Concentration & 4 & 159.210 & 39.802 & $11.028^{*}$ \\
\hline Error & 18 & 64.964 & 3.609 & \\
\hline Total & 26 & 1522.625 & & \\
\hline
\end{tabular}

Table 6.2 Comparison of the mean percentage mortality of Trogoderma granarium after exposure to different concentrations of plant extracts after $48 \mathrm{hrs}$

\begin{tabular}{|l|c|}
\hline Concentrations (\%) & Mean percentage of mortality \pm SE \\
\hline $\mathbf{5}$ & $5.14 \pm 0.72$ \\
\hline $\mathbf{1 0}$ & $13.40 \pm 1.92$ \\
\hline
\end{tabular}




\begin{tabular}{|l|c|}
\hline Concentrations $(\%)$ & Mean percentage of mortality \pm SE \\
\hline 15 & $17.53 \pm 2.65$ \\
\hline
\end{tabular}

Data in table 6.1. Represents the insecticidal effect of different concentrations of 3 different oil against Trogoderma granarium. The experimental data revealed that maximum mortality $(17.53 \%)$ at $15 \%$ was recorded. The mean mortality was $5.14 \%$ at $5 \%$ concentration and $13.40 \%$ mortality was observed at $10 \%$ concentration of the plant extracts. From this, it is inferred that mortality only increased with a rise in concentrations of a 3 different plant oil and shows also that concentration has a major impact on the mean percent mortality rate of $\mathrm{T}$. granarium.

6.2 Comparison of the mean percentage mortality of Trogoderma granarium after

exposure to different plant extracts after 48 hrs

\begin{tabular}{|l|c|}
\hline Concentrations (\%) & Mean percentage of mortality \pm SE \\
\hline P1 & $7.23 \pm 1.21$ \\
\hline P2 & $10.56 \pm 1.55$ \\
\hline P3 & $18.29 \pm 3.04$ \\
\hline
\end{tabular}

Table 6.3 For percent mean mortality values of different plant extracts at different concentration levels showed that extracts of $R$. communis and Jatropha curcus gave mortality values 18.29 and $10.56 \%$, correspondingly. While the least mortality $7.23 \%$ was given by extract of Citrus paradise.

6.4 Comparative mean percentage mortality of Trogoderma granarium after

exposure to different concentrations of plant extracts after $48 \mathrm{hrs}$

\begin{tabular}{|c|c|}
\hline Plant extracts x Concentrations (\%) & (\%) Mean Mortality \pm SE \\
\hline Citrus paradise $\mathrm{x} 5$ & $3.34 \pm 1.67 \mathrm{~g}$ \\
\hline Citrus paradise $\mathrm{x} 10$ & $8.34 \pm 1.67$ efg \\
\hline Citrus paradise $\mathrm{x} 15$ & $10.00 \pm 0.00 \mathrm{def}$ \\
\hline Jatropha curcus $\times 5$ & $5.00 \pm 0.00 \mathrm{fg}$ \\
\hline Jatropha curcus $\times 10$ & $11.67 \pm 1.67 \mathrm{~cd}$ \\
\hline Jatropha curcus $\mathrm{x} 15$ & $15.00 \pm 0.00 \mathrm{bc}$ \\
\hline Ricinus communis $\mathrm{x} 5$ & $7.07 \pm 0.00 \mathrm{de}$ \\
\hline Ricinus communis $\mathrm{x} 10$ & $20.20 \pm 1.014 b$ \\
\hline Ricinus communis $\mathrm{x} 15$ & $27.60 \pm 1.22 \mathrm{a}$ \\
\hline
\end{tabular}

This publication is licensed under Creative Commons Attribution CC BY. 
Table 6.4 showed the interaction between different concentrations (5, 10 and 15\%) and different exposure periods. Mean mortality of $T$. granarium was given in percentage by the application of an extract of Ricinus communis, Jatropha curcus, Citrus paradise oil along with the standard error in table 6.4.

The mean comparison of percentage mortality values of $T$. granarium at different concentrations of selected plant extract was highest at maximum concentration. Extract of Ricinus communis gave the highest mean mortality revealed that maximum mortality $(27.60 \%)$ at $15 \%$ was recorded. The mean mortality was $20.20 \%$ at $10 \%$ concentration and $7.07 \%$ mortality concentration of plant extracts was observed at 5 per cent. Extract of Jatropha curcus gave the mean mortality revealed that maximum mortality (15.00\%) at $15 \%$ was recorded. The mean mortality was $11.67 \%$ at $10 \%$ concentration and $5.00 \%$ mortality was observed at $5 \%$ concentration of the plant extracts. Extract of Citrus paradise gave the mean mortality revealed that maximum mortality (10.00\%) at $15 \%$ was recorded. The mean mortality was $8.34 \%$ at $10 \%$ concentration and $3.34 \%$ mortality was observed at 5 per cent plant extract concentration. The result given showed substantial association between exposure time and concentration. From the findings, we estimated that mortality values were rising slowly, with a rise in plant extract concentration.

\section{MORTALITY DATA AFTER EXPOSURE OF 72 HRS}

Table 7.1 Analysis of variance (ANOVA) of the data concerning $\%$ mortality of $T$. granarium (Herbst) for Titanium dioxide-based nanoparticles

\begin{tabular}{|l|l|l|l|l|}
\hline S.O.V & DF & SS & MSS & F value \\
\hline Plant & 2 & 619.787 & 309.894 & $55.938^{* *}$ \\
\hline Concentration & 2 & 1246.537 & 623.268 & $112.504^{* *}$ \\
\hline Plant*Concentration & 4 & 186.387 & 46.597 & $8.411^{*}$ \\
\hline Error & 18 & 99.719 & 5.540 & \\
\hline Total & 26 & & & \\
\hline
\end{tabular}

Table 7.2 Comparison of the mean percentage mortality of Trogoderma granarium after exposure to different concentrations of plant extracts after $72 \mathrm{hrs}$

\begin{tabular}{|l|c|}
\hline Concentrations (\%) & Mean percentage of mortality \pm SE \\
\hline $\mathbf{5}$ & $7.69 \pm 0.73$ \\
\hline $\mathbf{1 0}$ & $15.63 \pm 1.69$ \\
\hline $\mathbf{1 5}$ & $24.34 \pm 3.02$ \\
\hline
\end{tabular}

Data in table 7.1. Represents the insecticidal effect of different concentrations of 3 different oil against Trogoderma granarium. The experimental data revealed that maximum mortality $(24.34 \%)$ at $15 \%$ was recorded. The mean mortality was $7.69 \%$ at $5 \%$ concentration and $15.63 \%$ mortality was observed at a concentration of 10 per cent of plant extracts. From this, it is inferred that mortality only increased with a rise in concentrations of the 3 different plant oil and shows also that concentration has a major impact on the mean percent mortality rate of $\mathrm{T}$. granarium. 
7.3 Comparison of the mean percentage mortality of Trogoderma granarium after hrs exposure to different plant extracts after 72

\begin{tabular}{|l|c|}
\hline Concentrations (\%) & Mean percentage of mortality \pm SE \\
\hline P1 & $9.67 \pm 1.32$ \\
\hline P2 & $16.67 \pm 2.41$ \\
\hline P3 & $21.34 \pm 3.72$ \\
\hline
\end{tabular}

Table 7.4 for percent mean mortality values of different plant extracts at different concentration levels showed that extracts of $R$. communis and Jatropha curcus gave mortality values 21.34 and $16.67 \%$, correspondingly. While the least mortality $9.67 \%$ was given by extract of Citrus paradise.

7.5 Comparative mean percentage mortality of Trogoderma granarium after exposure to different concentrations of plant extracts after $72 \mathrm{hrs}$

\begin{tabular}{|c|c|}
\hline \begin{tabular}{|l} 
Plant extracts x Concentrations (\%) \\
\end{tabular} & (\%) Mean Mortality $\pm \mathrm{SE}$ \\
\hline Citrus paradise $\mathrm{x} 5$ & $5.00 \pm 0.00 \mathrm{~g}$ \\
\hline Citrus paradise $\mathrm{x} 10$ & $10.00 \pm 0.00 \mathrm{efg}$ \\
\hline Citrus paradise $\mathrm{x} 15$ & $14.00 \pm 0.57 \mathrm{def}$ \\
\hline Jatropha curcus $\mathrm{x} 5$ & $9.00 \pm 0.00 \mathrm{fg}$ \\
\hline Jatropha curcus $\times 10$ & $15.67 \pm 0.34 \mathrm{~cd}$ \\
\hline Jatropha curcus $\mathrm{x} 15$ & $25.34 \pm 1.34 \mathrm{bc}$ \\
\hline Ricinus communis $\mathrm{x} 5$ & $9.091 \pm 1.01 \mathrm{de}$ \\
\hline Ricinus communis $\mathrm{x} 10$ & $21.22 \pm 1.74 b$ \\
\hline Ricinus communis $\mathrm{x} 15$ & $33.68 \pm 3.21 \mathrm{a}$ \\
\hline
\end{tabular}

Table 7.6. Showed the interaction between different concentrations (5,10 and 15\%) and different exposure periods. Mean mortality of T. granarium was given in percentage by the application of an extract of Ricinus communis, Jatropha curcus, Citrus paradise oil along with the standard error in table 7.6.

The mean comparison of percentage mortality values of $T$. granarium at different concentrations of selected plant extract was highest at maximum concentration. Extract of Ricinus communis gave the highest mean mortality revealed that maximum mortality (33.68\%) at $15 \%$ was recorded. The mean mortality was $21.22 \%$ at $10 \%$ concentration and $9.091 \%$ mortality was observed at 5 per cent plant extract concentration. Extract of Jatropha curcus gave the mean mortality revealed that maximum mortality (25.34\%) at $15 \%$ was recorded. The mean mortality was $15.67 \%$ at $10 \%$ concentration and $9.00 \%$ mortality was observed at $5 \%$ concentration of the plant extracts. Extract of Citrus paradise gave the mean mortality revealed that maximum mortality (14.00\%) at $15 \%$ was recorded. The mean mortality was $10.00 \%$ at $10 \%$ concentration and $5.00 \%$ mortality of the plant extracts was observed at 5 percent. The given outcome 
showed that the interaction of exposure time and concentration was significant. From the findings, we estimated that mortality values were rising slowly, with a rise in plant extract concentration.

\section{Titanium Nano-composites}

\section{UV-VIS SPECTRA ANALYSIS}

The UV-Vis spectra were analysed to validate the presence of nanoparticles in the resulting solutions. UV-Vis absorption spectroscopy is an important technique for controlling the composition and consistency of aqueous solution in metal NPs. Metal NP's absorption range is susceptible to several variables like particle size, shape, and nano-particle interaction (agglomeration) with the

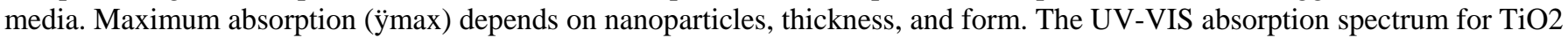
nanoparticles between 200 and $400 \mathrm{~nm}$ is shown in Figure $4.3 \mathrm{TiO} 2$ absorption occurs at $280 \mathrm{~nm}$, and its absorbance in UV - Vis spectroscopy will be 0.004. (Aryal et cetera, 2006).

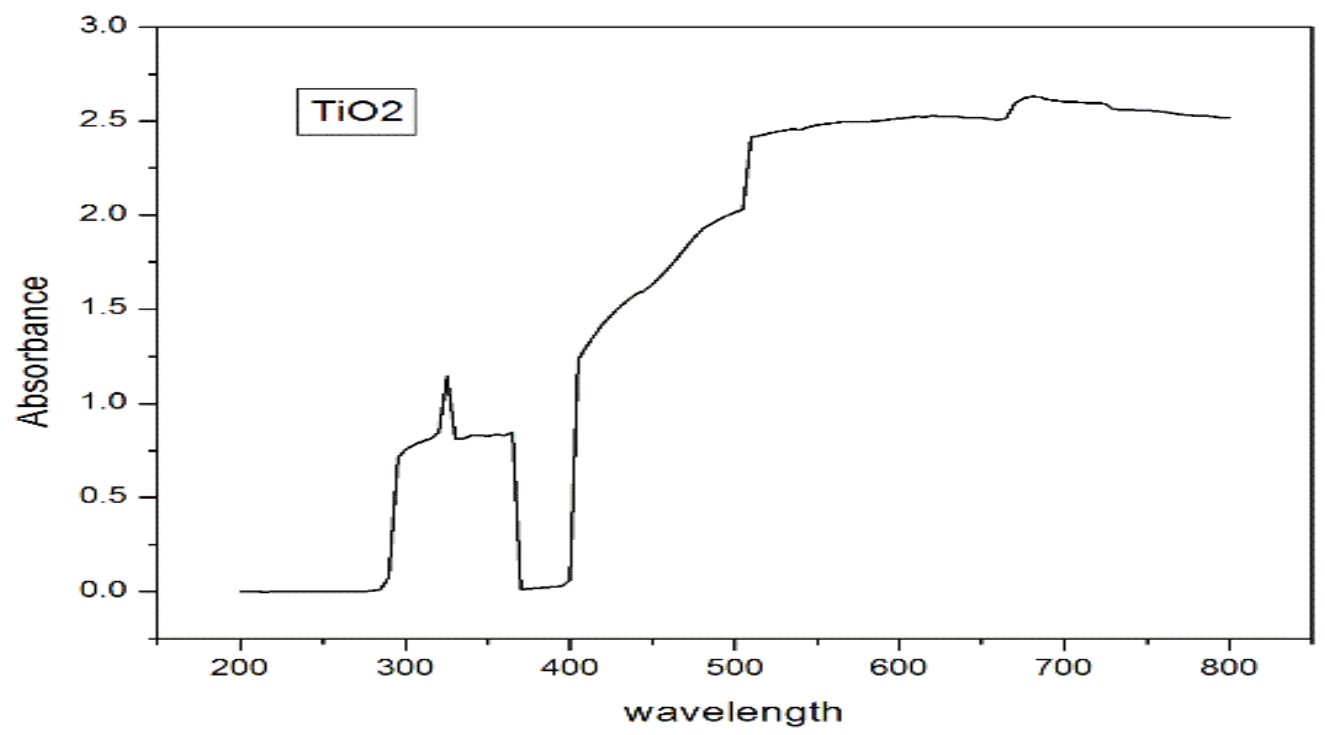

Figure 8.1: UV-Vis absorption spectra of titanium nanoparticle synthesized

\section{FOURIER TRANSFORMS INFRARED SPECTROSCOPY (FTIR)}

FTIR spectroscopy was used to classify various groups on Ricinus communis powder and to estimate their role in the formulation of nanoparticles. Figure 6 reveals the bands are at $3320 \mathrm{~cm}-1,1590 \mathrm{~cm}-1,1385 \mathrm{~cm}-1,1024 \mathrm{~cm}-1$. And $431-1 \mathrm{~cm}$. The TiO2 nanoparticles FTIR spectrum showed characteristic $1024 \mathrm{~cm}-1$ bands which indicate the presence of C-O stretching alcohols, carboxylic acids, esters, and ethers. The peak at $1385 \mathrm{~cm}-1$ indicates $\mathrm{C}-\mathrm{H}$ rock alkenes while the peak at $1590 \mathrm{~cm}-1$ indicates the presence of saturated hydrocarbon signature $\mathrm{C}=\mathrm{C}$. The $3320 \mathrm{~cm}-1$ band correlates to $\mathrm{O}-\mathrm{H}$, as do the alcohols and phenols bonded with $\mathrm{H}-$. Such bonds are related to the Ricinus communis chemical composition. In addition, the structure of Ricinus communis contains such compounds as caffeic acid, quinic acid and chlorogenic acid. It also contains free-form, glycosidally bound flavonoids (quercetin, kaempferol, rutoside, luteolin, apigenin, isorhamnetin), and essential oil. The peak at $431 \mathrm{~cm}-1$ shows TiO2 nanoparticles are present. 


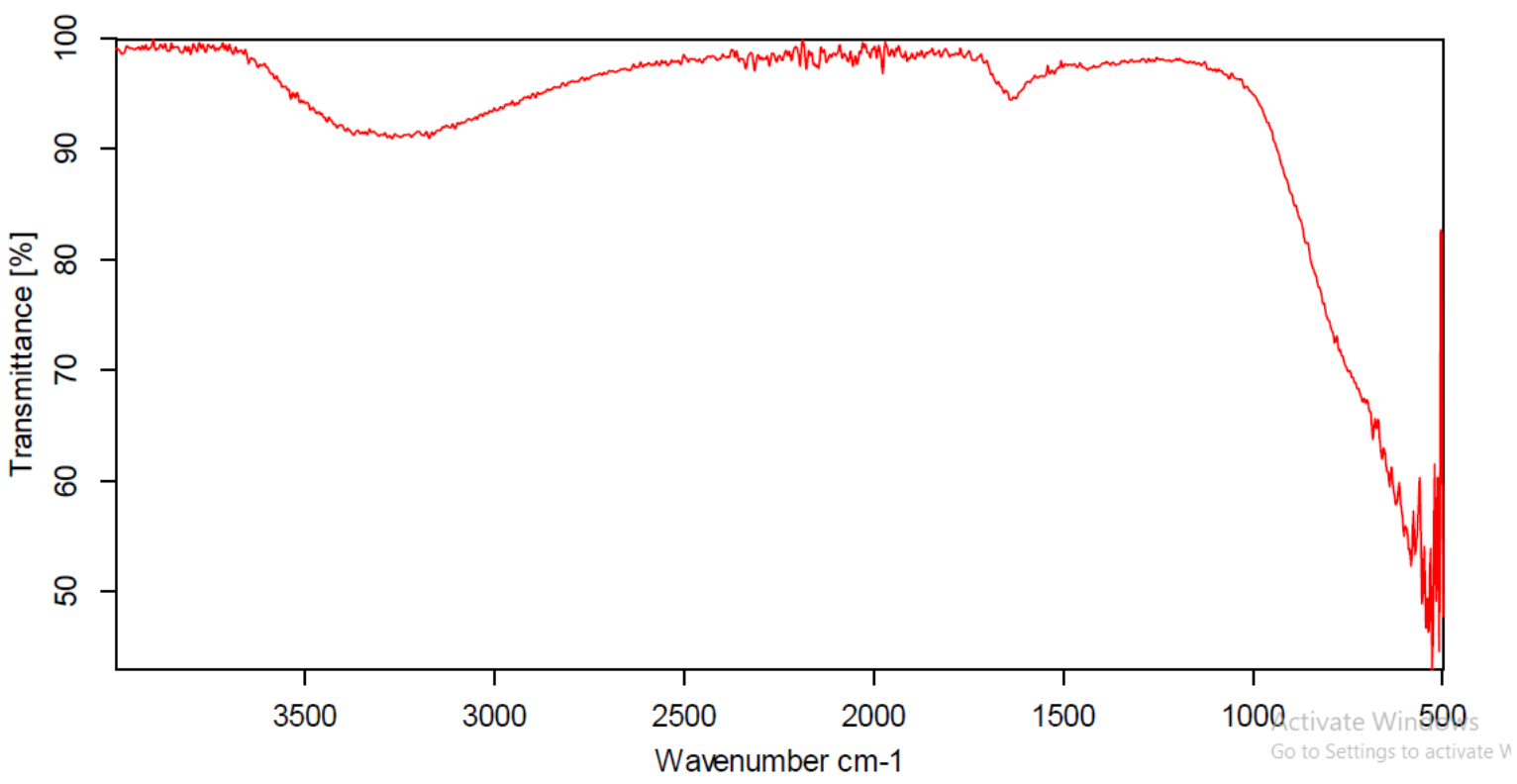

Figure 9.1 FTIR spectra of titanium dioxide nanoparticles

\section{CONCLUSION}

The present data demonstrate that green synthesis can also be used to prepare modern nanotechnology. These nanoparticles were synthesised with a variety of solvents derived from plant extracts. The pests Tribolium castanium and Trigoderma granarium have a significant impact on soil fertility and growth. In recent years, specific plant extract oil has been utilised to help manage these effects, although it will not work adequately. As a result, we can now monitor the enormous reproduction sickness in our country using nanoparticles. Our investigations demonstrate that the nanoparticles perform really effectively, and that the oil extracts quite simply as a result. The results presented will demonstrate that this is correct. Then we may conclude that nanoparticles are suggested for use at the farm level due to their low cost, availability, eco-friendliness, and effectiveness as an alternative method of pest management.

\section{REFERENCES}

[1] 1. Hao, Y., et al., Characterization of a major QTL for adult plant resistance to stripe rust in US soft red winter wheat. Theoretical and applied genetics, 2011. 123(8): p. 1401-1411.

[2] 2. Ramezani, H. and G.A. Mansoori, Diamondoids as molecular building blocks for nanotechnology, in Molecular Building Blocks for Nanotechnology. 2007, Springer. p. 44-71.

[3] 3. Peng, J., et al., Graphene quantum dots derived from carbon fibers. Nano letters, 2012. 12(2): p. 844-849.

[4] 4. Dagdeviren, C., et al., Conformal piezoelectric energy harvesting and storage from motions of the heart, lung, and diaphragm. Proceedings of the National Academy of Sciences, 2014. 111(5): p. 1927-1932.

[5] 5. Trindade, T., P. O'Brien, and N.L. Pickett, Nanocrystalline semiconductors: synthesis, properties, and perspectives. Chemistry of Materials, 2001. 13(11): p. 3843-3858.

[6] 6. Pérez-de-Luque, A. and D. Rubiales, Nanotechnology for parasitic plant control. Pest Management Science: formerly Pesticide Science, 2009. 65(5): p. 540545.

[7] 7. Ahmedani, M.S., et al., Khapra beetle (Trogoderma granarium Everts): A serious threat to food security and safety. Pak. J. Agri. Sci, 2007. 44(3): p. 481-493.

[8] 8. Phillips, T.W. and J.E. Throne, Biorational approaches to managing stored-product insects. Annual review of entomology, 2010.55.

[9] 9. Lu, H., et al., Effects of low-intensity microwave radiation on Tribolium castaneum physiological and biochemical characteristics and survival. Journal of insect physiology, 2010. 56(9): p. 1356-1361.

[10] 10. Ramzan, M. and B. Chahal, Effect of interspecific competition on the population build-up of some storage insects. Indian Journal of Ecology, 1986. 13(2): p. 313-317.

[11] 11. Parashar, M., Post harvest profile of black gram. Govt. India, Ministry of Agric. Deptt. Agric. and Coop. Directorate of Marketing and Inspection, Nagpur440001, 2006.

[12] 12. Arain, A., et al., Epilepsy and the impact of an epileptology clinic for patients with mental retardation and associated disabilities in an institutional setting. Epilepsia, 2006. 47(12): p. 2052-2057.

[13] 13. Jood, S. and A. Kapoor, Effect of storage and insect infestation on protein and starch digestibility of cereal grains. Food chemistry, 1992. 44(3): p. 209-212.

[14] 14. Khan, Z., J.I. Hussain, and A.A. Hashmi, Shape-directing role of cetyltrimethylammonium bromide in the green synthesis of Ag-nanoparticles using Neem (Azadirachta indica) leaf extract. Colloids and Surfaces B: Biointerfaces, 2012. 95: p. 229-234.

[15] 15. Miller, R., I. Tegen, and J. Perlwitz, Surface radiative forcing by soil dust aerosols and the hydrologic cycle. Journal of Geophysical Research: Atmospheres, 2004. 109(D4).

[16] 16. Taheriniya, S. and Z. Behboodi, Comparing green chemical methods and chemical methods for the synthesis of titanium dioxide nanoparticles. International Journal of Pharmaceutical Sciences and Research, 2016. 7(12): p. 4927. 


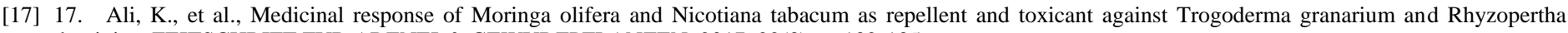
dominica. ZEITSCHRIFT FUR ARZNEI-\& GEWURZPFLANZEN, 2017. 22(3): p. 132-135.

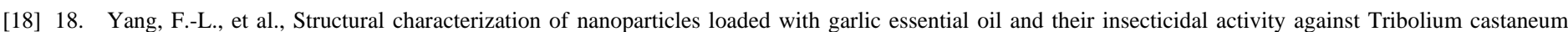
(Herbst)(Coleoptera: Tenebrionidae). Journal of agricultural and food chemistry, 2009. 57(21): p. 10156-10162.

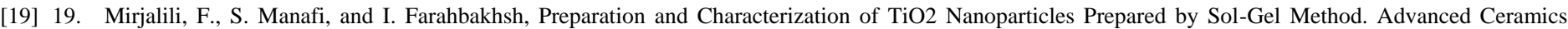
Progress, 2017. 3(3): p. 38-47.

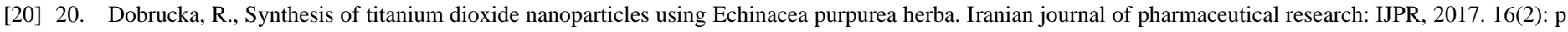
756.

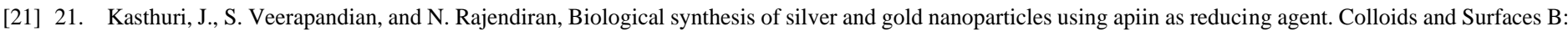
Biointerfaces, 2009. 68(1): p. 55-60.

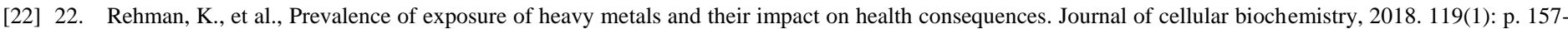
184.

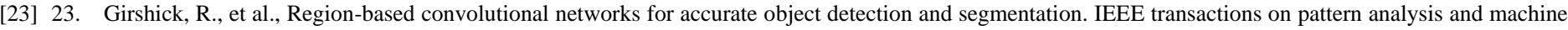
intelligence, 2015. 38(1): p. 142-158.

\section{AUTHORS}

First Author - Muhammad Nadeem Khan, epartment of chemistry, University of Lahore, Pakistan

Second Author - Muhammad Tahir, Department of chemistry, government college university Faisalabad 38000, Pakistan

Third Author - Samdullah, Department of chemistry, Shaheed Benazir Bhutto University Sheringal Dir Upper, Pakistan

Fourth Author - Imran Ahmad Khan, Department of chemistry, government college university Faisalabad 38000, Pakistan

Fifth Author - Waheb Aoun Jafari, Department of chemistry, University of Agriculture Faisalabad, Pakistan

Sixth Author - Shehreen Fatima, Department of chemistry, Bahauddin Zakariya University, Multan, Pakistan

Seventh Author - Muhammad Ishaq, Department of chemistry, University of Agriculture Faisalabad, Pakistan

Eighth Author - Muhammad Adnan, Department of chemistry, Bahauddin Zakariya University, Multan, Pakistan

Ninght Author - Muhammad Aqib Mukhtar, Department of chemistry, University of Agriculture Faisalabad, Pakistan 